\title{
Understanding cassava yield response to soil and fertilizer nutrient supply in West Africa
}

\author{
K. S. Ezui • A. C. Franke • B. D. K. Ahiabor • \\ F. M. Tetteh • J. Sogbedji • B. H. Janssen • A. Mando • \\ K. E. Giller
}

Received: 23 October 2016 / Accepted: 15 August 2017 /Published online: 8 September 2017

(C) The Author(s) 2017. This article is an open access publication

\begin{abstract}
Background and aims Enhanced understanding of plant and nutrient interactions is key to improving yields. We adapted the model for QUantitative Evaluation of the Fertility of Tropical Soils (QUEFTS) to assess cassava yield response to soil and fertilizer nutrients in West Africa. Methods Data from on-station and farmer's field experiments across Togo and Ghana were used.

Results Soil nutrient supply ranged from 86 to 177,18 24 and $70-104 \mathrm{~kg} \mathrm{ha}^{-1}$ of N, P and K, respectively, and induced variable cassava responses to fertilizer application. Considering harvest $(H I)$ in deriving the physiological nutrient use efficiencies for maximum dilution
\end{abstract}

Responsible Editor: John A. Kirkegaard.

K. S. Ezui · J. Sogbedji · A. Mando

International Fertilizer Development Centre (IFDC), North and

West Africa Division, BP 4483 Lomé, Togo

K. S. Ezui $(\bowtie) \cdot$ A. C. Franke $\cdot$ B. H. Janssen · K. E. Giller Plant Production Systems Group, Wageningen University, P.O. Box 430, 6700 AKWageningen, The Netherlands e-mail: sezui@yahoo.com

A. C. Franke

Soil, Crop and Climate Sciences, University of the Free State, Bloemfontein 9300, South Africa

B. D. K. Ahiabor

Savanna Agricultural Research Institute, CSIR-SARI, P.O. Box 52, Tamale, Ghana

F. M. Tetteh

Soil Research Institute, CSIR-SRI, Academy Post Office,

Kwadaso-Kumasi, Ghana
(PhEmax) and for maximum accumulation (PhEmin), which are key QUEFTS parameters, improved model predictions with reduction in normalized root mean square error from 32 to $13 \%$ at Davié (Southern Togo) and from 18 to $13 \%$ at Kumasi (Southern Ghana). Model overestimated yields in Nyankpala (Northern Ghana) where drought stress reduced yields. Estimated PhEmin and PhEmax at $H I$ of 0.50 were 41 and $96 \mathrm{~kg} \mathrm{~kg}^{-1} \mathrm{~N}$, 232 and $589 \mathrm{~kg} \mathrm{~kg}^{-1} \mathrm{P}$, and 34 and $160 \mathrm{~kg} \mathrm{~kg}^{-1} \mathrm{~K}$.

Conclusions QUEFTS can be used for site-specific estimates of cassava yield responses to fertilizers under rain-fed conditions in West Africa, provided that yield is primarily constrained by N, $\mathrm{P}$ and $\mathrm{K}$ supplies, and not by drought or other nutrients.

Keywords Soil nutrient supply · Fertilizer recovery fractions · QUEFTS · Togo · Ghana

\section{Introduction}

The differences between potential or attainable yields and actual yields, known as yield gaps, are large for cassava (Manihot esculenta, Crantz) in West Africa. Yields of fresh storage roots in smallholder farmers' fields average only 11.2 $\mathrm{Mg} \mathrm{ha}^{-1}$ (average 2000-2013) (FAOSTAT 2014), equal to about $4 \mathrm{Mg} \mathrm{ha}^{-1}$ storage root dry matter (DM). This yield is far less than yields of $60 \mathrm{Mg} \mathrm{ha}^{-1}$ (20-24 Mg ha ${ }^{-1}$ storage root DM) recorded in researcher-managed field experiments in the region (Odedina et al. 2009). A primary constraint is poor soil fertility resulting from the combination of inherently 
small soil nutrient stocks (Smaling et al. 1997) and continuous cropping with negligible nutrient inputs (Sanchez et al. 1997). Furthermore, soil fertility exhibits strong variability, both among and within farms (AdjeiNsiah et al. 2007) and fields, making blanket fertilizer recommendations inappropriate. Accurate assessment of nutrient supplies on a site-specific basis is important for enhanced estimates of crop yields. A sound understanding of nutrient uptake and nutrient conversion into crop yield is also required.

Despite the importance of cassava as a staple food and cash crop, there has been little attention for cassava yield predictions in response to nutrient supplies, uptakes and physiological use efficiency. The processoriented dynamic model CROPSIM cassava (Matthews and Hunt 1994; Singh et al. 1998) designed to simulate cassava growth and development was restricted to the assessment of potential, water-limited and nitrogen-limited yields. Thus, CROPSIM assumes that $\mathrm{P}$ and $\mathrm{K}$ are not limiting cassava growth, and is therefore not suited to assess nutrient limited yields in the nutrient depleted production systems of West Africa. Particularly, $\mathrm{K}$ deficiency is important in such low external nutrient use systems since cassava as a root crop has a high $\mathrm{K}$ demand (El-Sharkawy and Cadavid 2000; Howeler 2002; Pellet and El-Sharkawy 1997). The QUEFTS (QUantitative Evaluation of the Fertility of Tropical Soils) model could be a practical tool to assess nutrient requirements in cassava production systems. QUEFTS is a relatively simple and static model that predicts crop yields based on the interactions between the three macronutrients $\mathrm{N}, \mathrm{P}$ and $\mathrm{K}$, the physiological nutrient use efficiency $(P h E)$ of the crop and the climate and location specific maximum yield as boundary condition (Janssen and Guiking 1990; Janssen et al. 1990). QUEFTS was originally developed for soil fertility evaluation, nutrient requirements assessment and yield prediction for maize under tropical conditions (Janssen et al. 1990). It has been successfully tested in East Africa (Smaling and Janssen 1993), and thereafter adapted for other crops including rice (Haefele et al. 2003; Sattari et al. 2014; Witt et al. 1999), wheat (Pathak et al. 2003) and grain legumes (Franke et al. 2014) in various parts of the world. It has also been used to assess cassava yield and nutrient requirements under Indian conditions in Asia (Byju et al. 2012).

The evaluation of soil supply of nutrient by the original version of QUEFTS was based on soil chemical properties including a minimum dataset of soil organic carbon, available phosphorus, exchangeable potassium and pH (Janssen et al. 1990). However, soil supply of nutrients can also be determined from nutrient omission trials as the total plant uptake from one missing nutrient plots as described in the site-specific nutrient management system for rice production in India (Dobermann and White 1998; Witt et al. 1999). In the QUEFTS model adapted for cassava in India, the assessment of soil supply of nutrients has been done on a zone-specific basis leading to different equations relating soil chemical properties to soil nutrient stock estimates for each zone (Byju et al. 2012). The applicability of these equations for West Africa conditions has not yet been investigated.

The PhE, a key crop specific parameter of QUEFTS also called the internal nutrient use efficiency, is defined as the mass ratio of the economic components of a crop (grain, storage roots) to the quantity of nutrient uptake in the whole crop. As such, $P h E$ is sensitive to $H I$ (kg dry matter yield $\mathrm{kg}^{-1}$ total biomass dry matter), and to differences in the nutrient content of edible and other crop components (Sattari et al. 2014). Whereas cereals maintain most of their leaves until maturation or harvest, cassava leaf biomass is shed during dry seasons. For this reason, it is important to consider senesced leaves in the calculation of the total biomass produced, hence of HI. For cassava, differences in $H I$ between cultivars can be large. These were not considered in the QUEFTS model developed for cassava grown under Indian agroecological conditions (Byju et al. 2012), which prevents derivation of variety-specific fertilizer recommendations for cassava. Although $H I$ is measured at harvest, its value is known a priori for every cultivar as provided by breeders. However, besides genetics, HI strongly depends on the environment and management practices.

The current paper aims to assess cassava yield estimates as affected by $H I$, physiological nutrient use efficiency $(P h E)$, indigenous soil nutrient supplies and fertilizers in West Africa using the QUEFTS model. We hypothesized that accounting for the effects of $H I$ improves the yield prediction of cassava in West Africa, where different cultivars are grown with varying $H I$. We investigated the relationships between $\mathrm{N}, \mathrm{P}$ and $\mathrm{K}$ uptake and cassava yield and the relationship between soil parameters and quantities of soil $\mathrm{N}, \mathrm{P}$ and $\mathrm{K}$ supplies. This allowed us to calibrate and test the QUEFTS 
model, and predict cassava yields for different soil conditions and fertilizer amendments. For this purpose data from five different field experiments conducted between 2007 and 2010 in West Africa were used.

\section{Material and methods}

Model calibration

\section{Dataset for model calibration}

The dataset used for model calibration was collected in three field experiments conducted over two years in three agro-ecological zones (AEZ) of West Africa. The sites were Davié in Togo in the Coastal Savannah, Kumasi in the Deciduous Forest AEZ and Nyankpala in the Southern Guinea Savannah AEZ of Ghana (Table 1). Prior to crop establishment, soil samples were collected at five positions in each site up to $20 \mathrm{~cm}$ soil depth. Per site, these samples were mixed and a composite sample of $500 \mathrm{~g}$ was taken for laboratory analysis. Soils were analysed for soil organic carbon (SOC), soil total nitrogen, exchangeable cations, soil texture, $\mathrm{pH}-$ water, and available phosphorus (P-Bray-I) (Table 2), using the procedures described by Houba et al. (1995). The Rhodic Ferralsols at Davié is a loamy sand with known K deficiency (Table 2), the Ferric Acrisol at Kumasi is a silt loam with high SOC content, and the Gleyi-ferric lixisol at Nyankpala is sandy loam with low SOC content (Table 2) according to the soil fertility classification of Howeler (2002).
The experiments ran for two consecutive seasons at each site between 2007 and 2010 (Table 1). A randomised complete block design (RCBD) with replicates in four blocks and 10 fertilizer N-P-K rates $(\mathrm{kg} \mathrm{N}$, $\mathrm{P}$ and $\mathrm{K} \mathrm{ha}^{-1}: 0-0-0,0-40-130,40-40-130,80-0-130$, 80-20-130, 80-40-0, 80-40-65, 80-40-130, 40-20-65 and $100-50-170)$ was used. Nitrogen was applied as urea (46\%N, Davié and Kumasi) or sulphate of ammonia $(21 \% \mathrm{~N}$, Nyankpala), $\mathrm{P}$ as triple super phosphate (TSP: $20 \% \mathrm{P}$ ) and $\mathrm{K}$ as potassium chloride $(\mathrm{KCl}$ : $50 \% \mathrm{~K})$. All the TSP and one third of the urea and $\mathrm{KCl}$ were applied 30 days after planting (DAP); the remaining urea and $\mathrm{KCl}$ at 45 days after the first application. Soil bunds were constructed around each experimental plot to prevent lateral fertilizer contamination between plots. At each site, a locally-popular improved cassava cultivar was planted at the recommended planting density: "Gbazekoute" cultivar (TME-419) in Togo with a planting scheme of $0.8 \times 0.8 \mathrm{~m}\left(15,625\right.$ plants $\left.^{-1} \mathrm{ha}^{-1}\right)$ in $6.0 \times 5.6 \mathrm{~m}$ plots, and "Afisiafi” cultivar (TME-3281 or TME-771) in Ghana with a planting scheme of $1.0 \times 1.0 \mathrm{~m}\left(10,000\right.$ plants $\left.\mathrm{ha}^{-1}\right)$ in $7.0 \times 7.0 \mathrm{~m}$ plots. Hand weeding was carried out four times during the growing season.

Dry matter (DM) yields of storage roots and aboveground biomass (stem and leaves) were measured at final harvest on a harvest plot of $5.12 \mathrm{~m}^{2}$ (eight plant stands) per experimental plot excluding the two border rows. Sub-samples of each harvested plant part (leaf, stem, roots) of each treatment were oven-dried at $70^{\circ} \mathrm{C}$ to constant weight and DM mass fractions were determined. Dried plant organs were ground and digested using a $\mathrm{H}_{2} \mathrm{SO}_{4}-$ salicylic acid $-\mathrm{H}_{2} \mathrm{O}_{2}-$ Selenium

Table 1 Characteristics of the experimental sites for model parameterization

\begin{tabular}{llll}
\hline Site & Davié & Kumasi & Nyankpala \\
\hline Country, district & Togo, Maritime Region & Ghana, Ashanti Region & Ghana, Northern Region \\
Geographic coordinates & $6.385^{\circ} \mathrm{N}, 1.205^{\circ} \mathrm{E}$ & $6.686^{\circ} \mathrm{N}, 1.622^{\circ} \mathrm{W}$ & $9.396^{\circ} \mathrm{N}, 0.989^{\circ} \mathrm{W}$ \\
Altitude (m above sea level) & 89 & 267 & 170 \\
Soil type & Rhodic Ferralsols & Ferric Acrisol & Gleyi-ferric lixisol \\
Agro-ecological zone & Coastal Savannah & Deciduous Forest & Southern Guinea Savannah \\
Rainfall distribution & Bi-modal & Bi-modal & Mono-modal \\
Season 1 & May10-March 17, 2007-8 & June 28-March 22, 2008-9 & June 29 - Feb. 25, 2007-8 \\
Season 2 & April 26- Feb. 23, 2008-9 & June15-March15, 2009-10 & May 23 - Dec. 03, 2008 \\
Rainfall (mm, season 1 and 2) & 731,813 & 986,938 & 731,1017 \\
Cultivar & Gbazekoute & Afisiafi & Afisiafi \\
\hline
\end{tabular}


Table 2 Initial soil properties (0-20 cm soil depth) of the experimental sites used for model parameterisation and verification

\begin{tabular}{|c|c|c|c|c|c|c|c|c|c|}
\hline \multirow[t]{2}{*}{ Category and unit } & \multirow[t]{2}{*}{ Parameter } & \multicolumn{3}{|c|}{ Model parameterisation sites } & \multicolumn{5}{|c|}{ Model verification sites (Togo, Maritime Region) } \\
\hline & & Davié & Kumasi & Nyankpala & Gbave & $\begin{array}{l}\text { Davié } \\
\text { Tekpo }\end{array}$ & $\begin{array}{l}\text { Sévékpota } \\
\text { Black Soil }\end{array}$ & $\begin{array}{l}\text { Sévékpota White } \\
\text { Soil }\end{array}$ & $\begin{array}{l}\text { Sévékpota } \\
\text { Red Soil }\end{array}$ \\
\hline \multirow[t]{3}{*}{ Organic, $\mathrm{g} \mathrm{kg}^{-1}$} & SOC & 8.9 & 12.6 & 4.3 & 4.7 & 6.1 & 18.0 & 12.7 & 14.1 \\
\hline & SON & 0.7 & 1.5 & 0.3 & 0.3 & 0.4 & 1.4 & 0.9 & 1.1 \\
\hline & $\mathrm{C}: \mathrm{N}$ & 13.2 & 8.4 & 14.7 & 13.9 & 15.0 & 12.7 & 14.1 & 12.7 \\
\hline \multirow[t]{5}{*}{ Cations, $\mathrm{mmol} \mathrm{kg}^{-1}$} & $\mathrm{~K}$ & 1.5 & 3.8 & 3.1 & 2.2 & 1.9 & 6.2 & 4.0 & 4.3 \\
\hline & $\mathrm{Na}$ & 0.5 & 1.0 & 2.8 & - & - & - & - & - \\
\hline & $\mathrm{Ca}$ & 24.7 & 56.1 & 15.5 & 15.0 & 22.0 & 58.2 & 55.5 & 46.0 \\
\hline & $\mathrm{Mg}$ & 10.1 & 10.7 & 4.9 & 6.0 & 11.0 & 16.0 & 19.0 & 16.0 \\
\hline & $\mathrm{CEC}$ & 34.6 & 73.1 & 23.3 & 23.0 & 28.0 & 48.4 & 43.0 & 42.3 \\
\hline \multirow[t]{3}{*}{ Texture, $\mathrm{g} \mathrm{kg}^{-1}$} & Sand & 837 & 428 & 728 & 858 & 878 & 566 & 755 & 608 \\
\hline & Silt & 52 & 531 & 206 & 43 & 49 & 198 & 147 & 202 \\
\hline & Clay & 111 & 41 & 66 & 99 & 73 & 236 & 99 & 190 \\
\hline \multirow[t]{2}{*}{ Others } & $\mathrm{pH}-\mathrm{H}_{2} \mathrm{O}(1: 2.5)$ & 5.5 & 5.7 & 5.2 & 5.8 & 6.2 & 6.8 & 6.9 & 6.5 \\
\hline & P-Bray-I $\left(\mathrm{mg} \mathrm{kg}^{-1}\right)$ & 5.0 & 3.0 & 4.5 & 15.0 & 6.0 & 37.8 & 9.6 & 5.0 \\
\hline
\end{tabular}

mixture. Total $\mathrm{N}$ concentration was measured in this extract using a colorimetric method based on Berthelot's reaction (Sommer et al. 1992), total P concentration based on the method of the molybdo-phosphate complex with ascorbic acid as a reducing agent and $\mathrm{K}$ concentration by atomic absorption spectrophotometry using the Perkin Elmer model Analyst 400 (Houba et al. 1995).

\section{Yield prediction procedure of the original QUEFTS model}

The prediction of crop yield in response to nutrient supplies by QUEFTS follows four main steps (Janssen and Guiking 1990; Janssen et al. 1990). Step 1: the nutrient supply from soil and inputs of organic materials or fertilizer is estimated. Step 2: the uptake of a nutrient is calculated as a function of the total supply of that nutrient, and the interaction with the two other macronutrients; Step 3: for each nutrient uptake, two yields are calculated by the model, one corresponding to a situation where the nutrient is maximally diluted in the crop, and another one corresponding to a situation of maximum accumulation of that nutrient in the crop. Step 4: using the yield ranges defined in Step 3, the yield is calculated for each pair of nutrients, and the average yield of all pairs of nutrients is retained as the final yield estimate of the crop. These yields are calculated considering the climate and location-specific maximum yield of the cultivar as boundary condition.

Calibration of QUEFTS for cassava following the four steps for yield prediction of the model

Assessment of soil and input supplies of available nutrients (Step1) The supply of the total available nutrient (denoted as $T A \beta$ for a given nutrient $\beta$ ) for the crop was estimated from the supply of soil available nutrients $(S A \beta)$ and the supply from fertilizer inputs $(S I \beta)$ as follows:

$T A \beta=S A \beta+S I \beta$ with $S I \beta=M R F \beta \times I \beta$

Where $T A \beta$ is the total amount of available $\beta ; \beta$ stands for a given nutrient (N, P or K); $M R F$ for the apparent maximum recovery fraction of that nutrient; $I$ the amount of input (fertilizer nutrient) applied.

The assessment of $S A \beta$ followed two procedures to choose the one that matches better the experimental data (observed $S A \beta$ values). We first tested existing equations for assessing $S A \beta$ values (based on initial soil chemical properties comprising $\mathrm{pH}$, SOC, available $\mathrm{P}$ and exchangeable $\mathrm{K}$ measured before planting) used in previous QUEFTS versions. The latter included the original version by 
Janssen et al. (1990) as modified version by Sattari et al. (2014) and the version developed for cassava in India by Byju et al. (2012). For the latter, $S A \beta$ equations for Kerala and Andhra Pradesh cassava production zones (Byju et al. 2012) were used since P-Bray 1 was available. Subsequently, the values of $S A \beta$ and $S I \beta$ were graphically determined by plotting the observed maximum uptake ( $y$ axis) against fertilizer application rates ( $x$ axis) of a given nutrient. Given probable effects of fertilizer application on nutrient uptakes, all treatments with the same application rate of the relevant nutrient were used to calculate $S A \beta$ and $S I \beta$ to ensure that the maximum observed uptake of the nutrient of interest at a given rate is captured. For instance, the treatments assessed at $0 \mathrm{~kg} \mathrm{~N} \mathrm{ha}{ }^{-1}$ were $0-0-0$ and $0-40-130$; at $40 \mathrm{~kg}$ $\mathrm{N}$, these were 40-20-65 and 40-40-130; at $80 \mathrm{~kg}$ $\mathrm{N}$ ha $^{-1}$, these were $80-0-130,80-20-130,80-40-$ $0,80-40-65$ and 80-40-130. Among these treatments, the nutrient uptake in the treatment with the highest yield was taken as a proxy for $S A \beta+$ $S I \beta$, since the relevant nutrient was expected to be more limiting in this treatment than in the others. In addition, various percentiles (75th and 87.5 th) of the distribution of N, P and K uptakes were tested, as well as nutrient uptake in the treatments theoretically most appropriate for the purpose (e.g. 0-40-130, 40-40-130 and $80-40-130$ for $\mathrm{N}$ ). This was done per replicate as well as for the average of the four replicates. After these tests, it was decided to take the 75th percentile uptake found in all treatments with an equal application of the relevant nutrient. This selection was based on the fit between observed nutrient uptake and calculated nutrient uptake determined in Step 2 of QUEFTS (next Section). Where only two treatments could be compared (e.g. $0-0-0$ and $0-40-$ $130)$, the 75th percentile equalled: $L+0.75 \times(H-$ $L)$, where $L$ and $H$ stand for the lower and the higher value found in the two treatments. Plotting the calculated nutrient uptake ( $y$-axis) versus the fertilizer application rates of a nutrient ( $x$-axis) provided a linear regression of which the value of the intercept with the $y$-axis was used as $S A \beta$, and the slope was considered as $M R F \beta$.

Calculated uptake in relation to supply of nutrients (step 2) To calculate the uptake of each of the three nutrients, the original procedure of QUEFTS was followed (Janssen et al. 1990; Sattari et al. 2014). The uptake of nutrient 1 is calculated twice: i) as a function of the supplies of nutrients 1 and 2, and ii) as a function of the supplies of nutrients 1 and 3. The lesser of the two outcomes is considered more realistic following Liebig's law of the minimum and referred to as 'calculated nutrient uptake'. Calculated uptake of a given nutrient is less than the total supply. The latter refers to the maximum quantity of that nutrient that can be taken up. According to Janssen et al. (1990), the calculated uptake of a given nutrient equals the total supply only if all other growth conditions are optimum. Calculated nutrient uptakes were determined for each site based on specific $S A \beta$ and $S I \beta$ values, and compared to the observed uptakes.

Relationships between yield and nutrient uptake (steps 3 and 4 of QUEFTS) In Step 3, calculated nutrient uptake is converted into estimates of yield ranges based on the minimum and maximum $P h E$ of the relevant nutrient. Two approaches were tested to derive the minimum and maximum $P h E$ values from the model calibration dataset. The first approach (Approach 1) consisted of plotting observed nutrient uptake $(U \beta)$ in storage roots and tops (leaves plus stems) against observed storage root yield $(Y)$, and to determine upper and lower boundary lines (Byju et al. 2012; Janssen et al. 1990; Pathak et al. 2003; Witt et al. 1999). Following Witt et al. (1999), boundary lines for yields at maximum dilution $\left(Y_{d}\right)$ and maximum accumulation $\left(Y_{a}\right)$ were drawn based on data within the upper and lower 2.5 percentiles, respectively. The ratio of $Y \beta_{d} / U \beta$ represents the maximum $P h E$ (PhEmax), and the ratio $Y \beta_{a} / U \beta$ the minimum $P h E$ (PhEmin) of a given nutrient $\beta$. As recommended by several studies (Byju et al. 2012; Witt et al. 1999), to ensure that crop growth was mainly limited by nutrients, observations with an $H I$ less than 0.40 were removed (six observations were removed, corresponding to $2.5 \%$ of the dataset with in total 240 observations). It was assumed that the intercepts of the boundary lines with the $x$-axis, describing the minimum nutrient uptakes required to produce measurable yield (Janssen et al. 1990) were nil since even the smallest nutrient uptakes values in our dataset were enough to produce storage roots yields.

The alternative approach (Approach 2) to derive $P h E m i n$ and PhEmax was used recently in cereals yield 
predictions (Sattari et al. 2014) for situations with strongly varying values of $H I$. For cassava it holds:

$H I=$ Mass $_{\text {roots }} /\left(\right.$ Mass $_{\text {roots }}+$ Mass $\left._{\text {tops }}\right)=$ Mass $_{\text {roots }} /$ Mass $_{\text {total }}$

where Mass $_{\text {roots, }}$ Mass $_{\text {tops }}$ and Mass total stand for roots mass, tops mass and total (bio)mass respectively. Mass $_{\text {total }}$ is the sum of roots and tops masses.

Total uptake of a nutrient $(U \beta)$ is:

$U \beta=\left(\right.$ Mass roots $\times C \beta_{\text {roots }}+$ Mass $\left._{\text {tops }} \times C \beta_{\text {tops }}\right) / 1000$ or

$U \beta=\left[H I \times\right.$ Mass $_{\text {total }} \times C \beta_{\text {roots }}+(1-H I) \times$ Mass total $\left.\times C \beta_{\text {tops }}\right] / 1000$

where $C \beta_{\text {roots }}$ and $C \beta_{\text {tops }}$ are the mass fractions (g nutrient $\mathrm{kg}^{-1} \mathrm{DM}$ ) in cassava roots and tops, respectively, and $U \beta$ is expressed in $\mathrm{kg} \beta$ per ha. 1000 is a conversion factor from $\mathrm{g}$ to $\mathrm{kg}$.

$P h E \beta$, expressed in $\mathrm{kg} \mathrm{DM} \mathrm{kg}^{-1}$ nutrient, is:

$P h E \beta=$ Mass $_{\text {roots }} / U \beta=H I \times$ Mass $_{\text {total }} / U \beta$

Substitution of Eq. 3 in Eq. 4 yields:

$P h E \beta=1000 \times H I /\left(H I \times C \beta_{\text {roots }}+(1-H I) \times C \beta_{\text {tops }}\right)$

PhEmax and PhEmin values can be calculated as:

$P h E \beta \max =1000 \times \mathrm{HI} /\left(H I \times C \beta_{\text {roots,min }}+(1-H I) \times C \beta_{\text {tops,min }}\right)$

$P h E \beta \min =1000 \times H I /\left(H I \times C \beta_{\text {roots, } \max }+(1-H I) \times C \beta_{\text {tops, } \max }\right)$

where $C \beta_{\text {min }}$ and $C \beta_{\max }$ denote the minimum and maximum values of mass fractions $\left(\mathrm{g} \mathrm{kg}^{-1}\right)$ of a given nutrient. These values were obtained either from literature (Nijhof 1987) or derived from our model calibration experiments. We used $C \beta_{\min }$ and $C \beta_{\max }$ values of the entire dataset (model calibration experiments) to calculate PhEmax and PhEmin.

The two approaches to derive PhEmin and PhEmax values were tested based on the assumption that the best approach will provide the most accurate estimate of the yield if the estimates of the uptake of N, P and $\mathrm{K}$ are accurate (good fit between calculated and observed uptake of N, P and K). On that basis, Steps 3 and 4 were run to calculate yields with observed uptake of $\mathrm{N}$, $\mathrm{P}$ and $\mathrm{K}$ as input variables, and subsequently calculated yields were compared with observed yields. The approach providing the most accurate estimates of observed yields was applied in Step 2 of QUEFTS to calculate nutrient uptakes as a function of nutrient supplies. The medium $P h E$ denoted as PhEmed was calculated as the average value between PhEmax and PhEmin. The maximum yields obtained per site for each of the two growing seasons in the model calibration experiments were used as climate, location and cultivar specific maximum yield required as a boundary condition to run QUEFTS.

\section{Model testing}

Data collected in two additional on-farm fertilizer trials in Togo and Ghana were used to test model performance. Different rates of NPK fertilizers $\left(\mathrm{kg} \mathrm{ha}^{-1}\right)$ were used: 0-0-0, 20-10-80, 40-20-65, 60-25-120 and 10040-150 at Davié-Tekpo, Gbave and Sevekpota in Southern Togo, and NPK: 0-0-0, 48-0-95, 68-28-155, 82$28-155,98-55-183$ in Savelugu and Gbanlahi in Northern Region of Ghana. Fertilizer applications methods were the same as in the experiments described above. Except for Sevekpota where individual farmers hosted a single replicate of the 5 treatments ( 7 farmers in total), each farmer field at the other locations had four replicates laid out following a RCBD. Planting density followed recommended practices of each area. Healthy cuttings of 'Gbazekoute' cultivar were planted April 26, 2010 in southern Togo at a density of 15,625 plant ha ${ }^{-1}$ $(0.8 \times 0.8 \mathrm{~m}$ on $6.0 \times 5.6 \mathrm{~m}$ sub-plots $)$, and the storage roots were harvested on March 22, 2011. In Ghana, the planting of Afisiafi cultivar cuttings was performed on June 21, 2011 in Gbanlahi and on June 22, 2011 in Savelugu at a density of 10,000 plant $\mathrm{ha}^{-1}$ $(1.0 \times 1.0 \mathrm{~m}$ on $7.0 \times 7.0 \mathrm{~m}$ sub-plots $)$ and the harvest on December 18, 2012 and December 12, 2012 respectively. Data were collected on dry matter yields of storage roots, stems and leaves at all sites, and soil chemical data (obtained as described above in Section "Dataset for model calibration") from the Togolese sites only (Table 2).

The performance of the model was tested using the PhEmin and PhEmax values found to be best in the comparison of the two approaches (See Section "Relationship between yield and nutrient uptake"). Since no plant chemical data (plant N, P and $\mathrm{K}$ uptakes) and no minus one fertilizer nutrient treatments (nutrient omission treatments) were available in the model testing experiment, we assessed how well the model estimates cassava 
yield response to mineral fertilizer rates when the yield of the control plot (no fertilizer plot) is assumed well estimated by the model. Based on that principle, observed control plot yields were used to assess $S A \beta$ values at each site. For this reason, yield from control plots were excluded when testing the model performance. From a given starting value for each nutrient each location, $S A \beta$ were subsequently adjusted until good agreements were found between calculated and observed yields on the control plots. After $S A \beta$ values were obtained, the model's ability to estimate cassava yield in response to fertilizer applications was evaluated using only the treatments that did receive fertilizer in the model testing trials. The evaluation was done first with $M R F$ values derived from the model calibration trials. In following runs, $M R F$ values were adjusted per site to test model sensitivity to $M R F$ values and their effects on yield predictions of the model.

Model calculations were compared to observations using: the Root Mean Squared Error (RMSE), the Normalised Root Mean Squared Error (NRMSE) (Loague and Green 1991), the Willmott index of agreement (Willmott et al. 1985), the comparison with the 1:1 line, and the coefficient of determination $\left(R^{2}\right)$ and the regression line slope. Differences between sites in observed yields and uptake of $\mathrm{N}, \mathrm{P}$ and $\mathrm{K}$ were quantified using linear mixed models, with site as fixed factor, and year and block as random factors. The analysis of the differences in yields and uptake of N, P and $\mathrm{K}$ between years was done per site using general linear models. A probability threshold $P$ of 0.05 was used in all analyses to assess significance.

\section{Results}

Model calibration

Observed cassava storage roots yield and nutrient uptake

Storage root yields ( \pm standard deviation) significantly $(P<0.001)$ differed between sites when averaged over all 10 treatments in the model calibration experiments, and amounted 13,248 \pm 3144 , $10,544 \pm 3591$ and $6538 \pm 2228 \mathrm{~kg} \mathrm{ha}^{-1}$ in Davié,
Kumasi and Nyankpala, respectively. Yields obtained in 2008 were larger than those achieved in 2007 at Davié $\left(14,043 \mathrm{vs} 12,453 \mathrm{~kg} \mathrm{ha}^{-1}\right.$ respectively, $\left.P=0.023\right)$ and at Nyankpala (7745 vs $5331 \mathrm{~kg} \mathrm{ha}^{-1}$ respectively, $P<0.001)$ (Fig. 1); higher yields were also obtained in 2008 than in 2009 in Kumasi $\left(13,269\right.$ vs $7749 \mathrm{~kg} \mathrm{ha}^{-1}$ respectively, $P<0.001)$. The amount of rainfall during the growing season was highest in 2008 compared to 2007 in Davié and Nyankpala, and to 2009 in Kumasi (Table 1). Differences in nutrient uptakes between seasons reflected yields (Fig. 1). The largest total $\mathrm{N}$ and $\mathrm{P}$ uptake was found in Davié $(P<0.001)$ and the smallest in Nyankpala, whereas the smallest $\mathrm{K}$ uptake was obtained in Kumasi and the largest in Davié $(P<0.001)$. Averaged over all 10 treatments and growing seasons, total nutrient uptakes ( \pm standard deviation) per growing season were $196.3 \pm 62.4 \mathrm{~kg} \mathrm{~N}, 33.3 \pm 10.8 \mathrm{~kg} \mathrm{P}$ and $152.7 \pm 69.9 \mathrm{~kg} \mathrm{~K} \mathrm{ha}^{-1}$ in Davié, $100.8 \pm 26.9 \mathrm{~kg} \mathrm{~N}$, $22.3 \pm 6.8 \mathrm{~kg} \mathrm{P}$ and $68.0 \pm 24.4 \mathrm{~kg} \mathrm{~K}^{-1}$ in Kumasi, $103.5 \pm 35.5 \mathrm{~kg} \mathrm{~N}, 17.1 \pm 6.4 \mathrm{~kg} \mathrm{P}$ and $121.1 \pm 47.4 \mathrm{~kg}$ $\mathrm{K} \mathrm{ha}^{-1}$ in Nyankpala.

\section{Supply of available soil and fertilizer nutrients (step 1)}

The assessment of $S A \beta$ based on initial soil properties (Table 2) using equations by Janssen et al. (1990) (original QUEFTS) and by Byju et al. (2012) yielded large deviations relatively to the observed plant uptakes from one missing nutrient plots (Table 3). The SAP was strongly underestimated by both the Janssen et al. (1990) and Byju et al. (2012) equations for $S A \beta$ by $34-83 \%$. Deviations in estimating $S A N$ and $S A K$ were also large with both methods, ranging from underestimation by $12-84 \%$ for $\mathrm{N}$ to overestimation by 9 to $339 \%$ for $\mathrm{K}$. This indicates that $S A \beta$ equations by Janssen et al. (1990) defined for maize are not applicable for cassava. Likewise, $S A \beta$ equations of Byju et al. (2012) are not applicable to West African conditions, suggesting the need for their adaptation. Although, we had 240 observation points for plant uptake data, only three composite soil chemical and physical data were available for the three model calibration sites, and there was no plant $\mathrm{N}, \mathrm{P}$ and $\mathrm{K}$ uptake data from the five validation trial locations. Those were insufficient to derive strong relationships between $S A \beta$ and measured soil parameters. Under such circumstances, the alternative approach of assessing $S A \beta$ and $M R F \beta$ using linear regression approach appeared more appropriate and generated values that differed between sites (Table 4), 
a

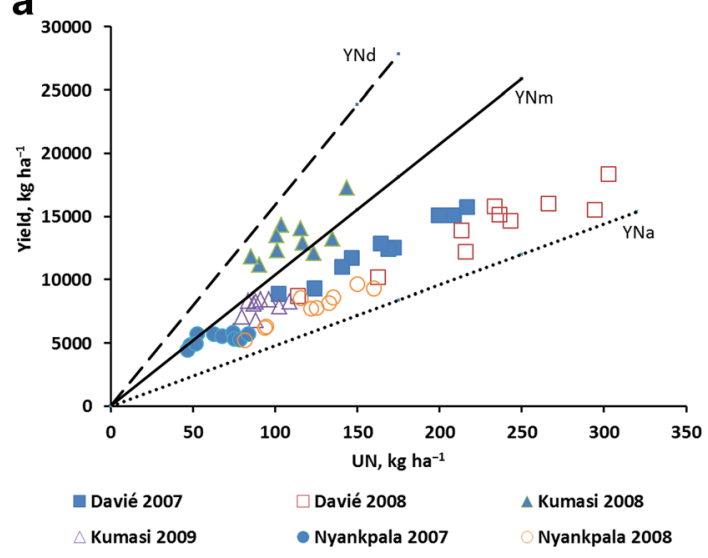

b

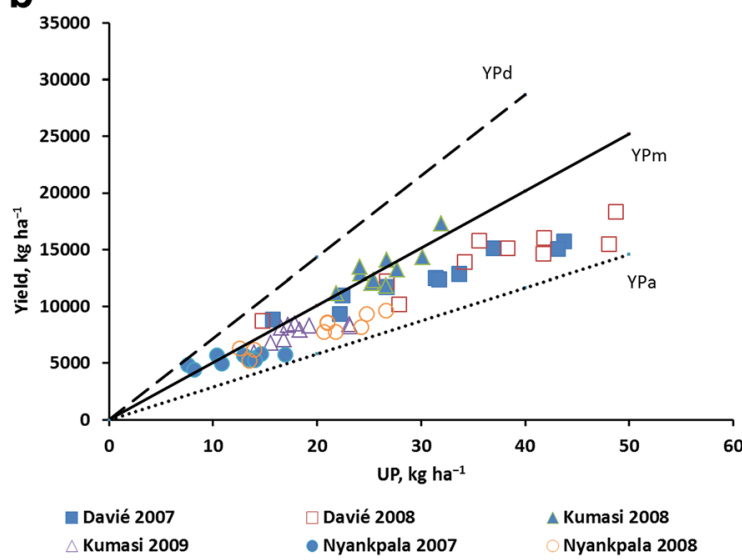

C

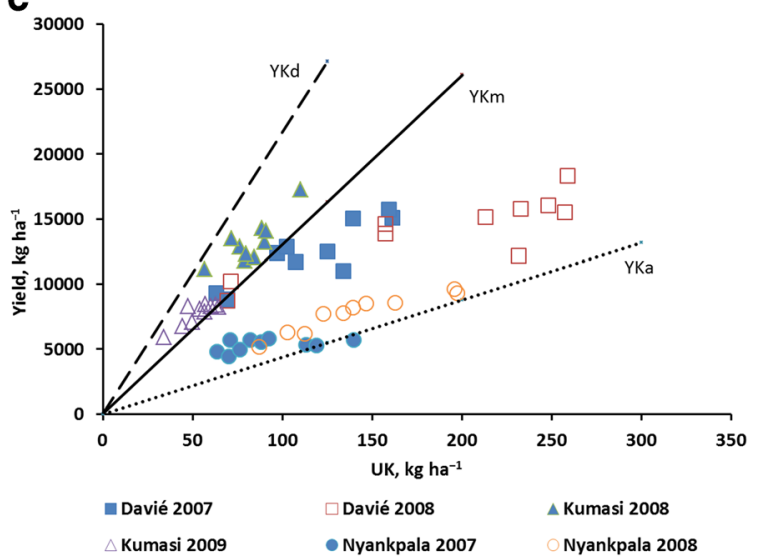

Fig. 1 Relationships between N, P and K uptakes and roots DM yields, and the estimated yields at maximum dilution and maximum accumulation of a nutrient $(Y \beta d$ and $Y \beta a)$, and the medium value between $Y \beta d$ and $Y \beta a(Y \beta m)$. Each point represents the average value of four replicates. Data from all the treatments (10 fertilizer combinations) of the model parameterisation experiment are included. The dry matter of cassava was on average $38 \%$ and $36 \%$ of fresh matter for Gbazekoute and Afisiafi respectively

especially for $\mathrm{N}$ and $\mathrm{K}$. The $S A \beta$ of $\mathrm{N}(S A N)$ decreased in the order of Davié > Kumasi > Nyankpala. Similarly, $S A \beta$ of K $(S A K)$ decreased in the order of Nyankpala $>$ Davié > Kumasi. The variation in $S A P$ ( $S A \beta$ for $\mathrm{P}$ ) between sites was small, since all three sites had soils with a low available $\mathrm{P}$ status (Table 2) according to Howeler (2002). In Davié, $M R F$ for $\mathrm{K}$ was very large (Table 4), likely due to the pronounced soil K deficiency there. However, a $M R F$ for $\mathrm{K}$ above $100 \%$ was not expected, though this phenomenon has also been reported by Pellet and El-Sharkawy (1997) as the result of the ability of the crop to remove large amounts of $\mathrm{K}$ from the soil. Values of $M R F$ at Kumasi were very small, suggesting limited external nutrient uptake and little nutrient limitations for cassava production. The SOC content on this site was larger than elsewhere (Table 2). The smaller $M R F$ for $\mathrm{K}$ at Nyankpala with a larger exchangeable K content when compared to Davié was expected.

Calculated uptake in relation to total supply of nutrients (step 2)

Nutrient uptakes calculated with Step 2 of QUEFTS were in good agreement with the observed uptakes of $\mathrm{N}, \mathrm{P}$ and $\mathrm{K}$ as indicated by the value of the slope of the regression line and $R^{2}$ close to 1 (Fig. 2). Regression analyses for each site separately gave slightly smaller $R^{2}$ values (not shown) than a single analysis for all sites together.

\section{Physiological nutrient use efficiency (steps 3 and 4)}

The two approaches for deriving PhEmin and PhEmax are illustrated in Fig. 1 (Approach 1, not $H I$ related) and Fig. 3 (Approach 2, HI related). In Approach 1, PhEmin and PhEmax values (Fig. 1) represent 2.5 and 97.5 th percentiles of all points and correspond to the boundary line for 
Table 3 Calculated SAN, SAP and SAK using original QUEFTS equations and Byju's equations for Kerala and Andhra Pradesh in India compared to mean plant uptakes $(U N, U P$ and $U K)$ from one missing nutrient plots

\begin{tabular}{|c|c|c|c|c|c|c|c|}
\hline \multirow[t]{2}{*}{ Site } & \multicolumn{3}{|c|}{ Soil available nutrients $\left(\mathrm{kg} \mathrm{ha}^{-1}\right)$} & \multirow[t]{2}{*}{ Observed uptake $\left(\mathrm{kg} \mathrm{ha}^{-1}\right)$} & \multicolumn{3}{|l|}{ Deviation (\%) } \\
\hline & Original QUEFTS & Kerala & Andhra Pradesh & & Original QUEFTS & Kerala & Andhra Pradesh \\
\hline & $S A N$ & & & $U N$ & & & \\
\hline Davié & 29.8 & 161.8 & 169.0 & 191.6 & -84 & -16 & -12 \\
\hline Kumasi & 68.9 & 231.7 & 216.7 & 100.1 & -31 & 131 & 116 \\
\hline \multirow[t]{2}{*}{ Nyankpala } & 11.2 & 75.0 & 109.6 & 66.9 & -83 & 12 & 64 \\
\hline & $S A P$ & & & $U P$ & & & \\
\hline Davié & 5.2 & 13.4 & 8.8 & 24.8 & -79 & -46 & -64 \\
\hline Kumasi & 5.7 & 10.7 & 5.9 & 22.7 & -75 & -53 & -74 \\
\hline \multirow[t]{2}{*}{ Nyankpala } & 3.3 & 12.8 & 8.2 & 19.4 & -83 & -34 & -58 \\
\hline & $S A K$ & & & $U K$ & & & \\
\hline Davié & 45.0 & 121.8 & 141.6 & 67.3 & -33 & 81 & 111 \\
\hline Kumasi & 79.8 & 251.4 & 322.1 & 73.4 & 9 & 243 & 339 \\
\hline Nyankpala & 174.3 & 256.8 & 329.5 & 91.3 & 91 & 181 & 261 \\
\hline
\end{tabular}

* $S A N$ ( $S A P$ and $S A K$ ) deviation is the relative difference between the value of estimated $S A$ and the observed plant uptake

maximum accumulation $\left(Y_{a}\right)$ and for maximum dilution $\left(Y_{d}\right)$ respectively. The six site/year combinations have different positions in the envelopes, with Kumasi 2008 being closer to the boundary line for maximum dilution $\left(Y_{d}\right)$ for $\mathrm{N}$ (Fig. 1a) and $\mathrm{K}$ (Fig. 1c), and Nyankpala closer to the boundary line of maximum accumulation $\left(Y_{a}\right)$, especially for $\mathrm{K}$. The points in the scatter graph of $\mathrm{P}$ uptake and roots yield (Fig. 1b) are closer together than those for $\mathrm{N}$ and $\mathrm{K}$ (Fig 1a, c, respectively), especially at low $\mathrm{P}$ uptake.

In Approach 2, the $H I$ and the minimum and maximum mass fractions in roots and tops (Table 5) were used in Eqs. 6 and 7 to derive PhEmax and PhEmin (Table 6). Measured root nutrient mass fractions were generally within the ranges given by Nijhof (1987). Fig. 3 shows that
$P h E$ varies with $H I$ across sites and years. It also shows that $P h E$ of $\mathrm{N}$ was small compared with literature since all points are situated between PhEmed and PhEmin of Nijhof (1987). Fig. 3 also shows that $P h E$ of $\mathrm{P}$ is within a comparable range across the three sites, and that $P h E$ of $\mathrm{K}$ is generally large at Davié and Kumasi but small at Nyankpala, pointing out large $K$ supply at the latter site. Furthermore, the largest values of $P h E$ of $\mathrm{K}$ were achieved at high $H I$ values, and vice versa, indicating that $P h E$ of $\mathrm{K}$ increases with $H I$.

The comparison of the two approaches to determine PhEmin and PhEmax suggested that Approach 2 worked better at Davié and Kumasi (Table 7). Although the performances of the two approaches were comparable in terms of $R^{2}$, Approach 2 provided more accuracy in the prediction with smaller RMSE and NRMSE, and a

Table 4 Maximum recovery fractions $(M R F)$ and soil supply of available nutrients $(S A \beta)$ graphically determined through the linear regression relating the maximum nutrient uptake to the rate of applied nutrients, and $R^{2}$ values of these linear regression equations

\begin{tabular}{|c|c|c|c|c|c|c|c|c|c|}
\hline \multirow[t]{2}{*}{ Variables } & \multicolumn{3}{|l|}{ Davié } & \multicolumn{3}{|c|}{ Kumasi } & \multicolumn{3}{|c|}{ Nyankpala } \\
\hline & $\mathrm{N}$ & $\mathrm{P}$ & $\mathrm{K}$ & $\mathrm{N}$ & $\mathrm{P}$ & K & $\mathrm{N}$ & $\mathrm{P}$ & $\mathrm{K}$ \\
\hline$R^{2}$ & 0.886 & 0.895 & 0.997 & 0.752 & 0.960 & 0.669 & 0.998 & 0.994 & 0.721 \\
\hline$M R F, \%$ & 69 & 44 & 105 & 33 & 15 & 10 & 49 & 3 & 33 \\
\hline$S A \beta, \mathrm{kg} \mathrm{ha}^{-1}$ & 177 & 24 & 70 & 94 & 21 & 65 & 86 & 18 & 104 \\
\hline
\end{tabular}

Maximum uptake was calculated as the 75th percentile of the uptakes of the plots with the same application rate of the relevant nutrient 

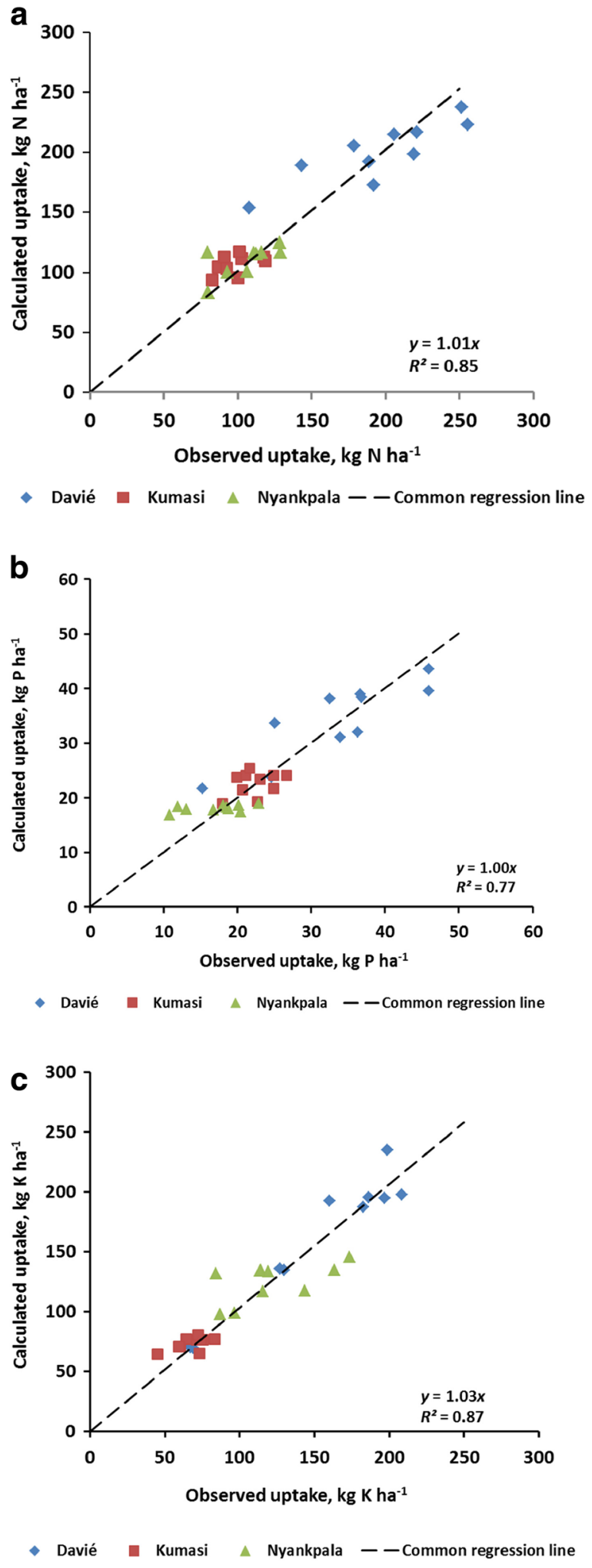

Fig. 2 Uptake of N (a), P (b) and K (c) as calculated in Step 2 in relation to observed uptake, and the associated regression line. Input variables for Step 2 were the soil and input supplies of nutrients estimated in Step 1. Each point represents the average observed uptake of eight values (four replicates, two seasons)

Willmott index closer to 1 . These results stress the importance of accounting for the influence of $H I$ on PhEmax and PhEmin in predicting cassava yields.

Model performance was best for Davié with calculated and observed yields scattered around the 1:1 line, and poorest for Nyankpala with an overestimation of observed yields by the model (Fig. 4). Since average values of $H I$ were used by QUEFTS whereas $H I$ varied over seasons, observed yields were overestimated in case the real $H I$ was smaller than the average $H I$, and underestimated in case the real $H I$ was larger than the average $H I$. At Nyankpala, calculated yields were much larger than observed yields (Figs 4 and 5). This is in agreement with the low $P h E$ values observed at this site, which suggests an inefficient nutrient use due to luxury nutrient uptake. Planting was late in Nyankpala in the first year (June 29, 2007), whereas the rainy season ran from April to October, meaning that the crop benefited from four months of rain at most. The second half of the growing season the crop likely suffered from drought, causing a low $P h E$.

The comparison of $P h E$ values using an hypothetical cultivar with an $H I$ value of 0.4 (Table 6) to those reported under Indian agro-ecological conditions by Byju et al. (2012) revealed that PhE values are higher in India, especially for $\mathrm{P}$, pointing to stronger $\mathrm{P}$ dilution than in West Africa. Only PhEKmax was higher in West Africa, reflecting poor $\mathrm{K}$ availability, which was especially evident on the Ferralsols in Davié (Fig. 3).

Yields in relation to the total supply of available nutrients (steps 1-4)

Using the calibrated QUEFTS (PhEmin, PhEmax and $H I$; Table 6), $S A \beta$ and $M R F$ values (Table 4), the best fit between observed and calculated yields were obtained at Davié (Fig. 5). At Kumasi, calculated and observed yields agreed better in 2008 than in 2009 (Fig. 5) when observed yields were smaller than calculated yields. The smaller observed yields in 2009 compared to 2008 were likely due to smaller amounts and inadequate distribution of rainfall in 2008. About $49 \%$ of total rainfall in the growing season (Table 1) occurred in the first month 

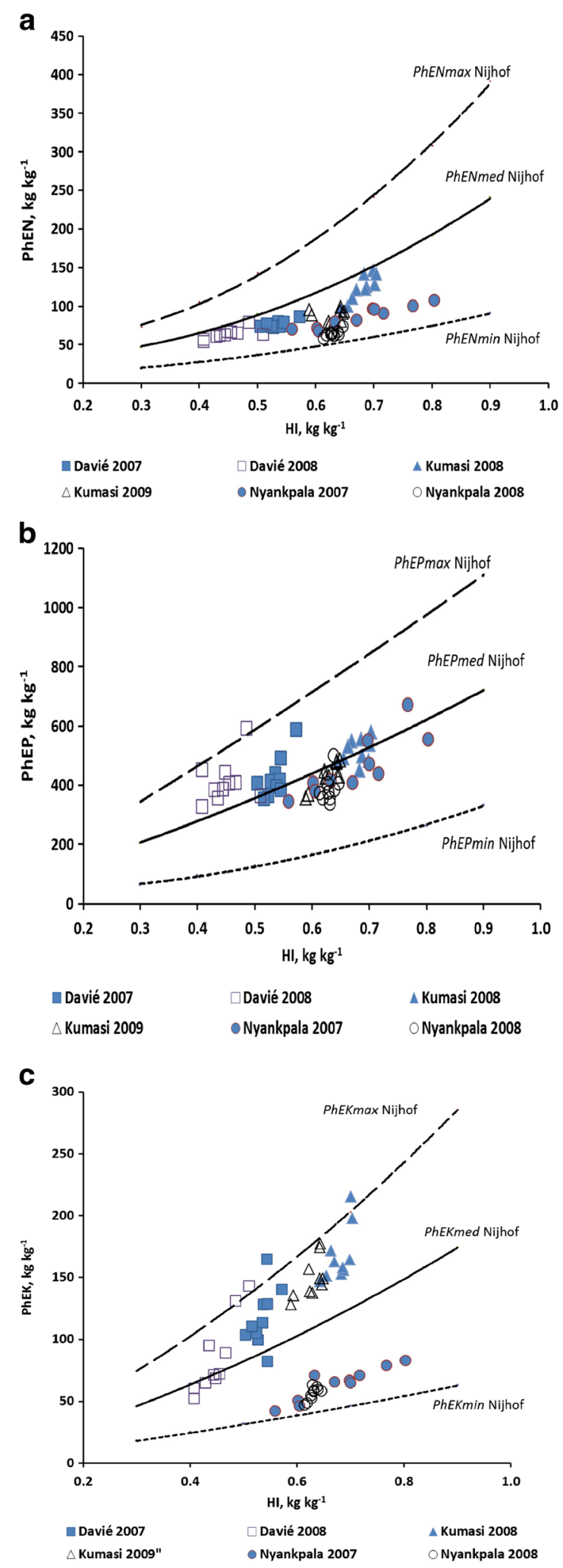

after planting (not shown). Most of this water was likely lost through evaporation as soil coverage by cassava was small in the first month after planting. At Nyankpala, calculated yields were strongly overestimated in both years (Figs 4 and 5). As suggested above, the growth conditions in Nyankpala during the first part of the growing seasons allowed the crop to take up available nutrients to produce top biomass, while drought likely limited growth later in the season, causing an inefficient translocation of photosynthetates to the storage roots, hence strongly hindering storage root yield.

\section{Model testing}

Calculated yields agreed well with observed yields (Fig. 6). This indicates that the model can effectively estimate cassava response to fertilizer N, P and K (Fig. 6a), provided that $S A \beta$ values are estimated in such a way to adequately assess yields on control plots. However, the use of site specific $M R F$ values slightly improved yield predictions (Fig. 6b), indicating that the difference between calculated and observed yields were at least partly due to differences in $M R F$ values between sites.

\section{Discussion}

This paper showed that the model can provide sound estimates of cassava yields when $S A \beta$ and $M R F \beta$ are accurately assessed and that PhEmin and PhEmax are estimated based on $H I$ in areas where $H I$ is very variable. The use of previous QUEFTS equations by Janssen et al. (1990) and Byju et al. (2012) for assessing $S A \beta$ underestimated $S A N$ by $12-84 \%$ and $S A P$ by $34-$ $83 \%$, and overestimated $S A K$ by $9-339 \%$ (Table 3 ). Most of $S A \beta$ values were underestimated by Janssen et al. (1990) equations for all three nutrients (Table 3) probably because such equations were developed for 
Table 5 Ranges between 2.5th and 97.5th percentiles of nutrient mass fractions ( $\mathrm{g}$ nutrient $\mathrm{kg}^{-1} \mathrm{DM}$ ) in cassava roots and tops, as found in literature (Nijhof, 1987) and in the present study for each cultivar and both cultivars combined

\begin{tabular}{|c|c|c|c|c|c|c|}
\hline \multirow[t]{2}{*}{ Source } & \multicolumn{3}{|l|}{ Roots } & \multicolumn{3}{|l|}{ Tops } \\
\hline & $\mathrm{N}$ & $\mathrm{P}$ & K & $\mathrm{N}$ & $\mathrm{P}$ & K \\
\hline Nijhof & $2.0-9.0$ & $0.8-2.4$ & $3.0-14.0$ & $5.0-18.0$ & $0.9-5.5$ & $4.5-18.0$ \\
\hline Gbazekoute & $2.8-5.1$ & $0.7-1.7$ & $2.8-7.7$ & $7.9-12.8$ & $0.9-1.7$ & $3.5-9.5$ \\
\hline Afisiasi & $2.5-6.9$ & $0.8-1.5$ & $3.0-11.0$ & 7.9-18.4 & $1.2-2.8$ & $3.4-19.8$ \\
\hline $\begin{array}{l}\text { Both } \\
\text { cultivars }\end{array}$ & $2.5-6.6$ & $0.8-1.5$ & $2.8-11.0$ & 7.9-17.9 & $0.9-2.8$ & $3.4-18.8$ \\
\hline
\end{tabular}

cereals, which have a much shorter growing period (34 months) than cassava (6 to more than 12 months). Moreover, cassava is more effective than cereals in $\mathrm{P}$ uptake under P-limiting conditions due to cassava's strong mycorrhizal symbiosis (Kang and Okeke 1984; Sieverding and Leihner 1984). In the case of the Byju et al. (2012) equations for assessing $S A \beta$, variable trends were observed for $S A N$, while $S A P$ was underestimated by $34-74 \%$ and $S A K$ overestimated by $81-339 \%$. Further improvement of the model should consider relationships between nutrient stocks and soil chemical properties in West Africa as well as links with crop duration, soil depth, management and rainfall that can affect nutrient supplies and uptake by cassava.

The alternative method adopted in this study by graphically assessing $S A \beta$ provided results that reflected differences between sites, especially for $\mathrm{N}$ and $\mathrm{K}$ (Table 4). The largest value of $S A \beta$ for $\mathrm{N}(S A N)$ was obtained at Davié, rather than Kumasi which had larger SOC, because Kumasi had larger PhE N for the same

Table 6 The HI and the corresponding PhEmin and PhEmax used in model calculations

\begin{tabular}{|c|c|c|c|c|c|c|c|}
\hline \multirow[t]{2}{*}{ Cultivar } & \multirow[t]{2}{*}{$H I$} & \multicolumn{3}{|c|}{ PhEmin } & \multicolumn{3}{|c|}{ PhEmax } \\
\hline & & $\mathrm{N}$ & $\mathrm{P}$ & $\mathrm{K}$ & $\mathrm{N}$ & $\mathrm{P}$ & $\mathrm{K}$ \\
\hline Gbazekoute-par & 0.50 & 41 & 232 & 34 & 96 & 589 & 160 \\
\hline Gbazekoute-ver & 0.55 & 47 & 262 & 38 & 112 & 653 & 178 \\
\hline Afisiafi-par & 0.65 & 61 & 329 & 47 & 148 & 782 & 214 \\
\hline Afisiafi-ver & 0.70 & 70 & 365 & 53 & 170 & 848 & 233 \\
\hline Hypothetical & 0.40 & 30 & 175 & 26 & 70 & 465 & 126 \\
\hline India & 0.40 & 35 & 250 & 32 & 80 & 750 & 102 \\
\hline
\end{tabular}

The abbreviations par and ver stand for parameterisation and verification experiments. To allow comparison with values found in India (Byju et al. 2012), $P h E$ values were also calculated for a hypothetical cultivar with an $H I$ of 0.40 amount of $\mathrm{N}$ uptake (Fig. 1a). Moreover, the $\mathrm{C}: \mathrm{N}$ ratio of Kumasi site was lower compared to Davié (Table 2), indicating higher SOC mineralization leading to higher $\mathrm{N}$ availability and susceptibility to losses in Kumasi. The highest $S A K$ was estimated at Nyankpala, because of the high availability of $\mathrm{K}$ in the soil (Table 2). Similar $S A P$ values were obtained across all sites since all sites were poor in available $P$.

The graphically estimated $M R F$ values (Table 4) also reflected soil nutrient availability across sites. The strong $\mathrm{K}$ deficiency explained the high $M R F$ of $\mathrm{K}$ at Davié. The large SOC at Kumasi with large soil N supply resulted in a relatively small $M R F$ of $\mathrm{N}$ at this site. The $M R F$ of $\mathrm{P}$ varied across sites, with the smallest value obtained at Nyankpala and the largest at Davié. Since all sites had soils with low available P, the differ-

Table 7 The ability of QUEFTS to predict observed yields using two different approaches to derive PhEmin and PhEmax

\begin{tabular}{|c|c|c|c|c|}
\hline $\begin{array}{l}P h E \text { boundary } \\
\text { lines approaches }\end{array}$ & Parameter & Davié & Nyankpala & Kumasi \\
\hline \multirow{5}{*}{$\begin{array}{l}\text { Approach 1: } \\
\text { Yield } \\
\text { to uptake } \\
\text { ratio }\end{array}$} & Slope & 1.28 & 1.42 & 0.86 \\
\hline & $R^{2}$ & 0.84 & 0.85 & 0.69 \\
\hline & $R M S E\left(\mathrm{~kg} \mathrm{ha}^{-1}\right)$ & 4226 & 3046 & 1843 \\
\hline & NRMSE $(\%)$ & 32 & 47 & 18 \\
\hline & $\begin{array}{l}\text { Willmott's } \\
\text { index }\end{array}$ & 0.742 & 0.690 & 0.872 \\
\hline \multirow{5}{*}{$\begin{array}{l}\text { Approach 2:HI } \\
\text { related } \\
\text { PhEmin } \\
\text { \& PhEmax }\end{array}$} & Slope & 1.00 & 1.55 & 0.95 \\
\hline & $R^{2}$ & 0.82 & 0.85 & 0.67 \\
\hline & RMSE $\left(\mathrm{kg} \mathrm{ha}^{-1}\right)$ & 1702 & 3941 & 1354 \\
\hline & NRMSE (\%) & 13 & 60 & 13 \\
\hline & $\begin{array}{l}\text { Willmott's } \\
\text { index }\end{array}$ & 0.932 & 0.604 & 0.930 \\
\hline
\end{tabular}

Slope and $R^{2}$ are relative to the linear regression line between calculated (y-axis) and measured ( $x$-axis) yields. The number of observations per site was 20 , with replicates averaged per season 

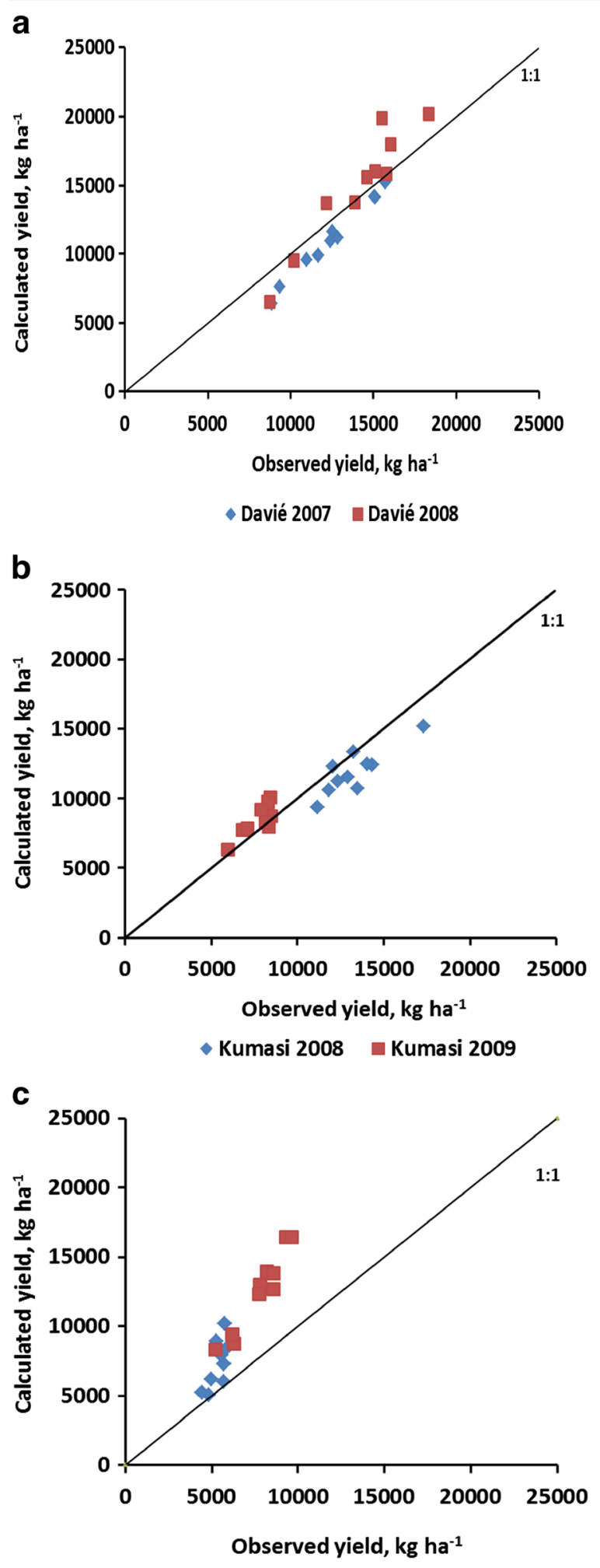

- Nyankpala 2007 Nyankpala 2008
Fig. 4 Relations between yields calculated with Step 3 and 4 of QUEFTS using $H I$ related $P h E$ boundary lines (Approach 2) and observed yields for Davié (a), Kumasi (b) and Nyankpala (c). Input variables for Step 3 were the observed nutrient uptakes. HI values were set at 0.50 for Davié and at 0.65 for Kumasi and Nyankpala. Each point represents the average yield of four replicates

ence in $M R F$ of $\mathrm{P}$ may be attributed to differences in $\mathrm{P}$ requirements to meet the yield potential across sites, and to mycorrhizal enhancing effects on P use efficiency of cassava (Kang and Okeke 1984; Sieverding and Leihner 1984).

The evaluation of the relationships between nutrient uptakes and yields of cassava showed that accurate estimates of nutrient uptakes resulted in accurate assessments of yields in Davié and $\mathrm{Ku}-$ masi (Fig. 4). This suggests that relationships characterized by PhEmax, PhEmin and HI (Eqs 6 and 7) provided a satisfying description of reality. Considering harvest $(H I)$ in deriving PhEmax and PhEmin improved model predictions with reduction in NRMSE from 32 to $13 \%$ at Davié (Southern Togo) and from 18 to $13 \%$ at Kumasi (Southern Ghana) (Table 7). The situation was different at Nyankpala where both approaches (with and without considering $H I$ in assessing PhEmax and PhEmin) generated high NRMSE values (47-60\%) indicating high deviations between observed and calculated yields. At Nyankpala, QUEFTScalculated yields were one and a half times larger than observed yields, which can be ascribed to the occurrence of drought while the crop was still in the active vegetative stage (Alves 2002). This constitutes a major limitation of the current versions of the model as the model applicability is limited in more arid zones, as in the case of Nyankpala in Northern Ghana. Process-based models with smaller time-step of integration to assess the growth at different stage of development of the plant are more relevant for these zones. Unfortunately the few existing process-based models are also constrained for the assessment of the dynamics of all the macronutrients, especially $\mathrm{K}$, which is important for cassava production in West Africa. An integrated approach combining QUEFTS with these process-based models could be useful under such growing conditions. However, at the moment, no validated process-based model for cassava is available under West African conditions. The 


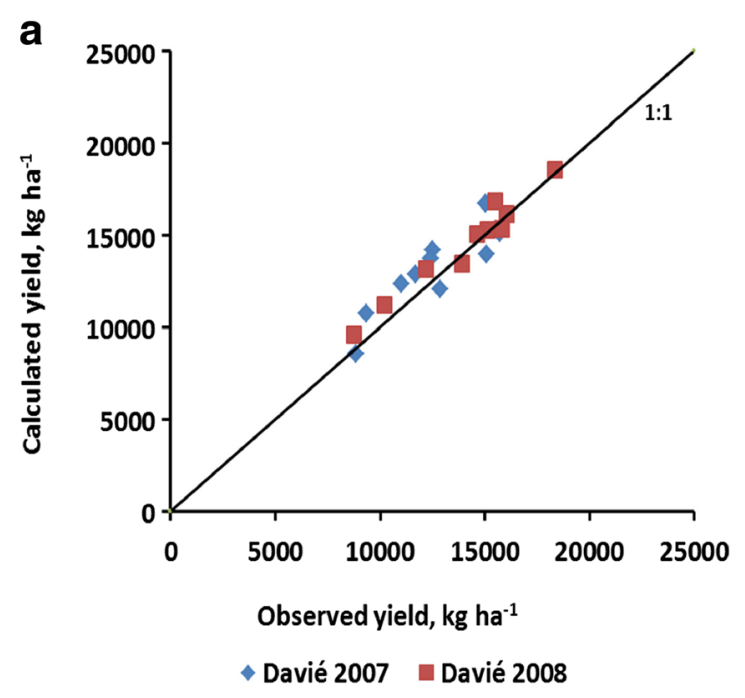

b
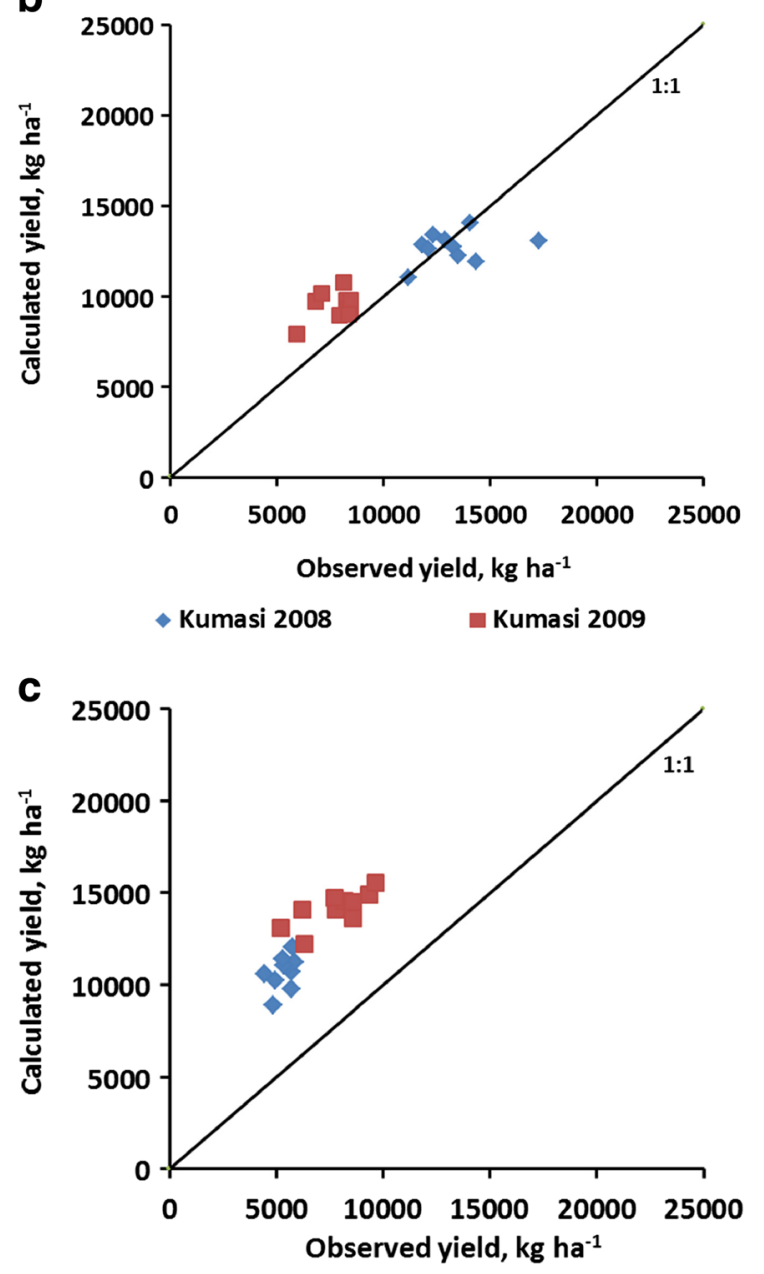

- Nyankpala 2007 Nyankpala 2008
Fig. 5 Yields calculated on the basis of estimated soil and input supplies of nutrients in relation to observed yields in Davié (a), Kumasi (b) and Nyankpala (c). Each point represents the average yield of four replicates

overestimation of yields at Nyankpala can also be attributed to nutrient deficiencies (other than $\mathrm{N}, \mathrm{P}$ and $\mathrm{K}$ ): the small concentration of magnesium (4.9 $\mathrm{mmol} \mathrm{kg} \mathrm{kg}^{-1}$ ) below the critical value of $6.0 \mathrm{mmol} \mathrm{kg}^{-1}$ for cassava (Snapp 1998), could have contributed to the overall weak response of cassava at this site. Strong yield responses to magnesium were obtained in Colombia on depleted soils (CIAT 1985).

The comparison of the studied cultivars with the Indian cultivars used by Byju et al. (2012) on the basis of an $H I$ value of 0.40 revealed that our cultivars had lower PhEmax for $\mathrm{P}$ and higher PhEmax for K (Table 6). In other words, they diluted less $\mathrm{P}$ and more $\mathrm{K}$ than the Indian cultivars. This suggests that the physiological use efficiency of $\mathrm{P}$ can be further improved in West Africa. Breeding to improve the dependency of cassava cultivars on mycorrhizal association for higher P use efficiency could contribute to improving this $\mathrm{P}$ physiological use efficiency, which will lift up the physiological use efficiency of $\mathrm{N}$ and K. Since higher physiological use efficiency of nutrient implies reduced nutrient requirement for the same target yield, this will generate larger returns on investments to farmers. The higher PhEmax for $\mathrm{K}$ of the cultivars grown in our study compared to the Indian cultivar is due to the fact that $\mathrm{K}$ was very deficient and the most limiting nutrient for cassava on the Ferralsols in Davié, as also observed on the Ferralsols in Southern Benin (Carsky and Toukourou 2005).

Calculated yields were close to observed values in the model testing experiments (Fig. 6). With $S A \beta$ estimates set at a value that QUEFTS compared best to observed control plot yields, the model was able to properly predict cassava responses to combined N, P and K applications. The absence of plant and soil chemical analyses data to derive $S A \beta$ is common in sub-Saharan Africa. The method used in this paper of deriving $S A \beta$ from control plots without fertilizer can be used when observed yield data from these plots are available. In case yields and plant $\mathrm{N}, \mathrm{P}$ and $\mathrm{K}$ content data from nutrient 


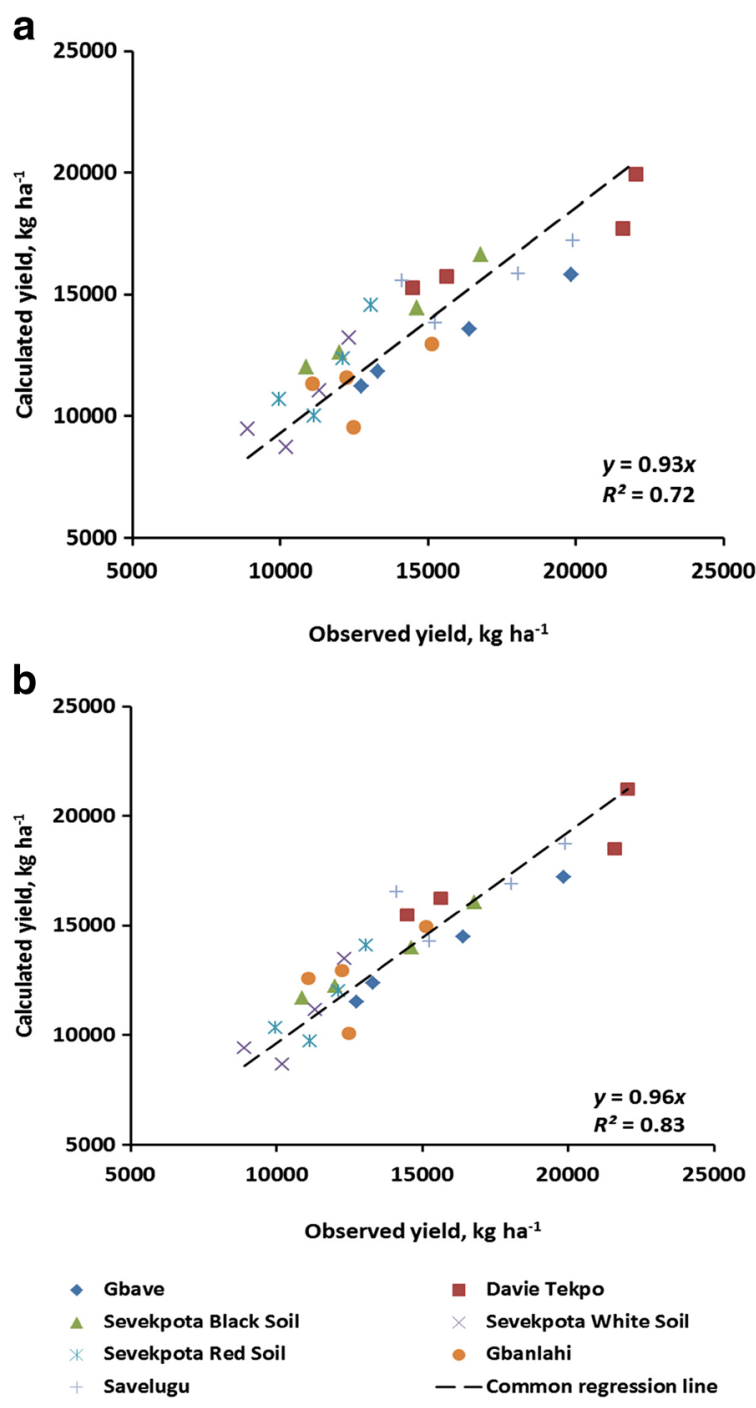

Fig. 6 Calculated yields in relation to observed yields in the model verification trials with common $M R F$ values (a) or adjusted per site (b). Input variables for Step 1 were estimated soil supplies of available nutrients of Table 8 and maximum recovery fractions of Tables 4 (Fig. 6a) and 8 (Fig. 6b). Each point represents the average yield of two to five replicates

omission trials (Dobermann et al. 2002; Witt et al. 1999) are available, plant uptakes from one missing nutrient plots can be used as proxy for $S A \beta$. However, nutrient omission trials cannot be conducted everywhere, hence the need to have sufficient soil data to relate plant uptakes from these nutrient omission plots with soil chemical data that are more available in order to ease the extrapolation of the results. Otherwise, the method used in the model parameterization trial in this paper can be applied. This latter method has the advantage of providing a good proxy of the maximum recovery fractions $(M R F \beta)$ as the slope of the regression line between the maximum plant uptake and the fertilizer rate of a given nutrient, along with the $S A \beta$ assessed as the intercept of this regression line. However, the availability of plant and soil chemical data is ideal to relate $S A \beta$ to soil parameters like in Step 1 equations of the original version of QUEFTS. The calculations were further improved by use of site specific $M R F$ values (Fig. 6b), highlighting the importance of location specific soil nutrient management for achieving higher cassava yields.

\section{Conclusions}

QUEFTS was adapted to estimate cassava yield and responses to mineral fertilizers under rain-fed conditions in West Africa. In years with normal rainfall, the model calculations produced yield estimates close to those observed, but the model overestimated yields under drought conditions. While the current model could be improved through further model testing experiments in other locations in West Africa and with the development of equations for estimating $S A \beta$ to cassava based on soil properties, it provides a useful tool for estimating cassava yield response to fertilizer applications. The strong crop responses to $\mathrm{N}, \mathrm{P}$ and $\mathrm{K}$ highlight the importance of replenishing soil nutrients through external nutrient supplies in cassava production systems. Moreover, our study highlighted the importance of relating the estimates of $P h E$ for maximum accumulation and $P h E$ for maximum dilution to $H I$ in cassava. Since $P h E$ increased with $H I$, plant breeders should work towards developing cultivars with enhanced $H I$ to improve nutrient use efficiency and yields in cassava production systems in West Africa.

Acknowledgements We are grateful to many researchers and support staff that contributed in different ways for the successful completion of this study funded by DGIS through the SAADA project implemented by the International Fertilizer Development Centre (IFDC). 
Table 8 Soil supplies of available N, P and K $(S A \beta)$, yields from control plots without fertilizer application $\left(Y_{0}\right)$ in the verification experiment, and the apparent maximum recovery fractions of fertilizer nutrients $(M R F \beta)$ estimated with the help of the model (Table 6)

\begin{tabular}{|c|c|c|c|c|c|c|c|}
\hline \multirow[t]{2}{*}{ Sites } & \multirow{2}{*}{$\begin{array}{l}Y_{0} \\
\mathrm{~kg} \mathrm{ha}^{-1}\end{array}$} & \multicolumn{3}{|c|}{$S A \beta, \mathrm{kg} \mathrm{ha}^{-1}$} & \multicolumn{3}{|c|}{$M R F \beta$} \\
\hline & & $\mathrm{N}$ & $\mathrm{P}$ & $\mathrm{K}$ & $\mathrm{N}$ & $\mathrm{P}$ & $\mathrm{K}$ \\
\hline Gbave & 7682 & 170 & 23 & 67 & 0.95 & 0.60 & 0.95 \\
\hline Davié Tekpo & 11801 & 250 & 34 & 99 & 0.95 & 0.60 & 0.95 \\
\hline Sévékpota Black Soil & 8728 & 186 & 25 & 74 & 0.69 & 0.44 & 0.80 \\
\hline Sévékpota White Soil & 5752 & 122 & 17 & 48 & 0.81 & 0.51 & 0.80 \\
\hline Sévékpota Red Soil & 6927 & 147 & 20 & 58 & 0.69 & 0.44 & 0.80 \\
\hline Average Togo & 8178 & 175 & 24 & 69 & 0.82 & 0.52 & 0.86 \\
\hline Gbanlahi & 7955 & 74 & 15 & 89 & 0.69 & 0.21 & 0.46 \\
\hline Savelegu & 12190 & 113 & 24 & 136 & 0.64 & 0.20 & 0.43 \\
\hline Average Ghana & 10073 & 93 & 20 & 113 & 0.66 & 0.20 & 0.45 \\
\hline General average & 9125 & 134 & 22 & 91 & 0.74 & 0.36 & 0.65 \\
\hline
\end{tabular}

Open Access This article is distributed under the terms of the Creative Commons Attribution 4.0 International License (http:// creativecommons.org/licenses/by/4.0/), which permits unrestricted use, distribution, and reproduction in any medium, provided you give appropriate credit to the original author(s) and the source, provide a link to the Creative Commons license, and indicate if changes were made.

\section{References}

Adjei-Nsiah S, Kuyper TW, Leeuwis C, Abekoe MK, Giller KE (2007) Evaluating sustainable and profitable cropping sequences with cassava and four legume crops: effects on soil fertility and maize yields in the forest/savannah transitional agro-ecological zone of Ghana. Field Crop Res 103:87-97

Alves AAC (2002) Cassava botany and physiology. In: Hillocks RJ, Thresh JM, Bellotti AC (eds) Cassava: biology, production and utilization. CABI, Wallingford

Byju G, Nedunchezhiyan M, Ravindran CS, Santhosh Mithra VS, Ravi V, Naskar SK (2012) Modeling the response of cassava to fertilizers: a site-specific nutrient management approach for greater tuberous root yield. Commun Soil Sci Plant Anal 43:1149-1162

Carsky RJ, Toukourou MA (2005) Identification of nutrients limiting cassava yield maintenance on a sedimentary soil in southern Benin, West Africa. Nutr Cycl Agroecosyst 71:151-162

CIAT (1985) Cassava program. In: CIAT (ed) annual report for 1982 and 1983. CIAT, Cali

Dobermann A, White PF (1998) Strategies for nutrient management in irrigated and rainfed lowland rice systems. Nutr Cycl Agroecosyst 53:1-18

Dobermann A, Witt C, Dawe D, Abdulrachman S, Gines HC, Nagarajan R, Satawathananont S, Son TT, Tan PS, Wang GH
(2002) Site-specific nutrient management for intensive rice cropping systems in Asia. Field Crop Res 74:37-66

El-Sharkawy MA, Cadavid LF (2000) Genetic variation within cassava germplasm in response to potassium. Exp Agric 36: 323-334

FAOSTAT (2014) FAO statistics. FAO Statistics Division, Rome

Franke AC, van den Brand GJ, Giller KE (2014) Which farmers benefit most from sustainable intensification? An ex-ante impact assessment of expanding grain legume production in Malawi. Eur J Agron 58:28-38

Haefele SM, Wopereis MCS, Ndiaye MK, Barro SE, Ould Isselmou M (2003) Internal nutrient efficiencies, fertilizer recovery rates and indigenous nutrient supply of irrigated lowland rice in Sahelian West Africa. Field Crop Res 80: 19-32

Houba VJG, Van der Lee JJ, Novozamsky I (1995) Soil analysis procedures, other procedures. vol. 5B. Wageningen Agricultural University, Wageningen, pp 217

Howeler RH (2002) Cassava mineral nutrition and fertilization. In: Hillocks RJ, Thresh JM, Bellotti AC (eds) Cassava: biology, production and utilization. CABI, Wallingford

Janssen BH, Guiking FCT (1990) Modelling the response of crops to fertilizers. In: van Beusichem ML (ed) Plant nutrition physiology and applications. Kluwer Academic Publishers, Dordrecht

Janssen BH, Guiking FCT, van der Eijk D, Smaling EMA, Wolf J, van Reuler H (1990) A system for quantitative evaluation of the fertility of tropical soils (QUEFTS). Geoderma 46:299-318

Kang BT, Okeke JE (1984) Nitrogen and potassium responses of two cassava varieties grown on an alfisol in southern Nigeria. Proceedings, 6th symposium International Society of Tropical Root Crops, lima, Peru, 21-26 February 1983, pp 231-37

Loague K, Green RE (1991) Statistical and graphical methods for evaluating solute transport models: overview and application. J Contam Hydrol 7 (1-2):51-73 
Matthews RB, Hunt LA (1994) GUMCAS: a model describing the growth of cassava (Manihot Esculenta L. Crantz). Field Crop Res 36:69-84

Nijhof K (1987) Concentration of macro-elements in economic products and residues of (sub)tropical field crops. Staff working paper SWO-87-08 52

Odedina SA, Odedina JN, Ogunkoya MO, Ojeniyi SO (2009) Agronomic evaluation of new cassava varieties introduced to farmers in Nigeria. In: African crop science conference proceedings. African Crop Science Society, Uganda, pp 77-80

Pathak H, Aggarwal PK, Roetter R, Kalra N, Bandyopadhaya SK, Prasad S, Van Keulen H (2003) Modelling the quantitative evaluation of soil nutrient supply, nutrient use efficiency, and fertilizer requirements of wheat in India. Nutr Cycl Agroecosyst 65:105-113

Pellet DM, El-Sharkawy MA (1997) Cassava varietal response to fertilization: growth dynamics and implications for cropping sustainability. Exp Agric 33:353-365

Sanchez PA, Shepherd KD, Soule MJ, Place FM, Buresh RJ, Izac A-MN, Mokwunye AU, Kwesiga FR, Ndiritu CG, Woomer PL (1997) Soil fertility replenishment in Africa: an investment in natural resource capital. In: Buresh RJ, Sanchez PA, Calhoun FG (eds) Replenishing soil fertility in Africa. Soil Science Society of America and America Society of Agronomy, Madison

Sattari SZ, van Ittersum MK, Bouwman AF, Smit AL, Janssen BH (2014) Crop yield response to soil fertility and N, P, K inputs in different environments: testing and improving the QUEFTS model. Field Crop Res 157:35-46
Sieverding E, Leihner DE (1984) Influence of crop rotation and intercropping of cassava with legumes on VA mycorrhizal symbiosis of cassava. Plant Soil 80:143-146

Singh U, Matthews RB, Griffin TS, Ritchie JT, Hunt LA, Goenaga R (1998) Modeling growth and development of root and tuber crops. Systems Approaches for Sustainable Agricultural Development 7:129-156

Smaling EMA, Janssen BH (1993) Calibration of quefts, a model predicting nutrient uptake and yields from chemical soil fertility indices. Geoderma 59:21-44

Smaling EMA, Nandwa SM, Janssen BH (1997) Soil fertility in Africa is at stake! In: Buresh RJ, Sanchez PA, Calhoun FG (eds) Replenishing soil fertility in Africa. Soil Science Society of America and American Society of Agronomy, Wisconsin

Snapp SS (1998) Soil nutrient status of smallholder farms in Malawi. Commun Soil Sci Plant Anal 29:2571-2588

Sommer SG, Kjellerup V, Kristjansen O (1992) Determination of total ammonium nitrogen in pig and cattle slurry - sample preparation and analysis. Acta Agriculturae Scandinavica Section B-Soil and Plant Science 42:146-151

Willmott CJ, Ackleson SG, Davis RE, Feddema JJ, Klink KM, Legates DR, O'Donnell J, Rowe CM (1985) Statistics for the evaluation and comparison of models. J Geophys Res 90 (C5):8995

Witt C, Dobermann A, Abdulrachman S, Gines HC, Guanghuo W, Nagarajan R, Satawatananont S, Thuc Son T, Sy Tan P, Van Tiem L (1999) Internal nutrient efficiencies of irrigated lowland rice in tropical and subtropical Asia. Field Crop Res 63: 113-138 